Motrivivência Ano XXI, No 32/33, P. 211-229 Jun-Dez./2009

\title{
AS REPRESENTAÇÕES SOCIAIS DO ATO PEDAGÓGICO DOS PROFESSORES DE EDUCAÇÃO FÍSICA QUE ATUAM NO ENSINO FUNDAMENTAL NO MUNICÍPIO DO RIO DE JANEIRO
}

Moebus José Retondar

\begin{abstract}
Resumo
O objetivo da pesquisa é identificar as representações sociais do ato pedagógico dos professores de educação física que atuam no ensino fundamental no Município do Rio de Janeiro. Para tal foi feito um levantamento panorâmico e sintético da história da educação física e do contexto da educação física escolar, bem como, a demarcação da noção de representação social. Foi aplicado 1 (um) questionário aberto, com 13 (treze) perguntas, a 16 (dezesseis) professores de educação física, da rede municipal de ensino, da cidade do Rio de Janeiro, que ministram aulas no ensino fundamental, sobre o modo como pensam sua prática e como fundamentam a sua intervenção e a sua profissão. Ao analisarmos os discursos
\end{abstract}

\section{Abstract}

The main purpose of this research is to identify social representations of elementary physical education teachers of public schools in Rio de Janeiro city. In the first moment we have made a panoramic view about physical education history as well as a revision of the concept of social representation. We applied an opened questioner with 13 questions to 16 elementary teachers from public schools of Rio de Janeiro city about how they think their practices and how they embassy their work and their intervention on reality. Analyzing the discourses of the teachers, in a perspective of Orlandi, we have been saw that they think

1 Departamento de Ginástica e Dança/UERJ. Área Educação Física Escolar e Imaginário social sobre as atividades corporais e lúdicas. Contato: retondar@oi.com.br 
à luz da perspectiva interpretativa de Orlandi, identificamos que o professor se auto percebe como um educador e, ao mesmo tempo, demonstra inúmeras contradições teóricas e conceituais entre o seu pensar e o seu fazer. Consegue fundamentar a sua prática por um único viés, que é a psicomotricidade, ainda que verbalize sobre a formação integral do aluno.

Palavras-chave: Educação Física; Representação Social; Município do Rio de janeiro. about their selves as educators as well as we can identify some contradictions between their actions and their theoretical reflexions, for example, they see their practices as essentially based on Psychomotricity, but say, at the same time, that their work is conducted to the integral formation of the student.

Keywords: Physical education;

Social representation;

Rio de Janeiro city.

\section{Introdução}

Durante o período de janeiro a dezembro de 2008, foi desenvolvidoa no Laboratório do Imaginário e das Representações Sociais Sobre as Atividades Corporais e Lúdicas da UERJ, sob coordenação do professor Jéferson Retondar, a pesquisa intitulada As Representações Sociais do Ato Pedagógico dos Professores de Educação Física que Atuam no Ensino Fundamental no Município do Rio De Janeiro, tendo sido apoiada pela Fundação de Amparo à Pesquisa do Estado do Rio de Janeiro - FAPERJ no Programa PROINICIAR.

O Programa de Iniciação Acadêmica - PROINICIAR é voltado para os alunos de Graduação da Universidade do Estado do Rio de Janeiro- UERJ, preferencialmente aqueles que ingressaram por meio da lei que regulamenta o Sistema de Cotas; Seu principal objetivo é apoiar o estudante, de modo a garantir-lhe a permanência na Universidade.

O objetivo da pesquisa foi identificar as Representações Sociais que fundamentam o ato pedagógico do professor de educação física, no contexto do ensino fundamental na rede municipal de ensino, da cidade do Rio de Janeiro.

$\mathrm{Na}$ tese de doutorado do professor Adriano Rosa (2007), sobre o Discurso Antidisciplinar da Educação Física Escolar, aponta uma enorme tensão e dificuldade de consenso sobre determinados conceitos e noções relativos à prática da educação física de maneira geral e em espacial da educação física escolar, como, por exemplo, as noções de corpo, de movimento, de um possível objeto de estudo da educação física, dos métodos de ensino, das formas de avaliação e de 
Ano XXI, n 32/33, junho e dezembro/2009

medida. $\mathrm{O}$ que remete a inúmeras repercussões filosóficas sobre os valores que são veiculados a partir de uma dada concepção de educação física e de ensino.

No site www.pcrj.rj.gov. br, da Secretaria de Educação do Município do Rio de Janeiro, consta que hoje há 3600 ( três mil e seiscentos) professores de Educação Física, atuando em 1058 escolas, e que atendem a 700 mil alunos. Considerando este universo, a pesquisa se justifica na medida em que busca pensar a prática pedagógica da educação física considerando a produção de sentidos elaborada pelos próprios professores. Os resultados obtidos poderão subsidiar novas intervenções considerando a realidade das representações que se encontram vigorando neste contexto.

\section{A educação física e seu enrai- zamento histórico}

Oliveira (1998) nos mostra que ao longo do século XIX, a Educação Física no Brasil é dominada intelectualmente por médicos e de maneira empírica pelos militares. À essa época, criam-se as primeiras Escolas de Educação Física visando a formar especialistas da área, como, por exemplo, em 1933, com a criação da Escola de Educação Física do Exército. Daí, a Educação Física escolar no ensino primário e médio terem sido ministradas, nessa época, por sargentos e por civis, ambos formados por instrutores e professores do Exército Brasileiro. Disso decorre o perfil do professor ou instrutor de Educação Física na Escola voltado, exclusivamente, para a idéia do fortalecimento do corpo, de sua limpeza, da civilidade e da utilidade para com a sociedade do trabalho e de futuros recrutas que irão defender o país no ambiente da caserna.

Neste contexto, os fundamentos teóricos e metodológicos do Ensino da Educação Física baseavam-se nos estudos da fisiologia, da biologia e das leis da física aplicada à biomecânica do movimento, à fisiologia do exercício e do esforço, ao treinamento desportivo e ao ensino das técnicas e dos fundamentos dos esportes consagrados, pois é papel precípuo das aulas de Educação Física na Escola produzirem corpos fortes, organicamente saudáveis, com capacidade de realizar movimentos com eficácia e com um determinado desempenho sob a égide ideológica de que assim seriam adultos prontos para enfrentar e superar o adversário nas competições e nas disputas do mundo do trabalho e no mundo da vida. Dessa forma, a ginástica calistênica ou calistenia é que irá se sobressair como conteúdo principal das aulas de educação física, bem como, a necessidade de separação 
entre meninos e meninas durante as aulas, haja vista por estas últimas serem consideradas frágeis e inaptas para a prática de determinada carga e intensidade de exercícios repetitivos, valor social dominante e ainda identificável na prática de muitos professores de educação física em nossa atualidade .

Soares (2002), em Imagens da Educação no Corpo, já havia situado esta discussão numa perspectiva também histórica ao mostrar que no início do século XIX com o advento do surgimento do capitalismo na Europa, em especial na Inglaterra, a lógica da nova ordem da produção, da organização, do consumo e da distribuição dos bens sociais, estas, amparadas pela ideologia da ciência como arauto da razão e do progresso social, faz com que o corpo e os movimentos corporais sejam alvos de controle e de poder através do ensino da ginástica, orientada pela primeira vez por um caráter "científico", utilitário e a serviço de uma lógica dominante da produção e do consumo social. Ou seja, a sociedade capitalista emergente, necessita de corpos fortes, com gestos eficazes e organicamente saudáveis para dar conta de jornadas de trabalho extenuantes, monótonas e repetitivas, bem como, corpos que interiorizem uma concepção moral de limpeza, de higiene e de saúde individual para se manterem aptos para o enfrentamento da vida sem sucumbirem às usas exigências, isto é, corpos disciplinados e obedientes à lógica dominante da sociedade. Diferente, por exemplo, do movimento espontâneo e gratuito realizado no circo, cujo conhecimento é passado de geração para geração sem qualquer amparo das ciências biológicas e físicas e cujo objetivo último é o de alegrar e divertir as pessoas, ou seja, a produção do circo não visa bens ou qualquer outro tipo de finalidade utilitária a não ser a divulgação da alegria, da fantasia e da magia para as pessoas por meio dos movimentos acrobáticos, do equilibrismo, da destreza e da comicidade em geral.

Ghiraldelli (1994), também numa perspectiva histórica, ao fazer um balanço histórico das tendências em educação física no Brasil, aponta que até aproximadamente 1930 a tendência higienista de educação física predominou, evocando o discurso da importância da educação física para a saúde orgânica, onde se buscava a limpeza e a assepsia de um corpo forte e funcionalmente capaz. Já a tendência militarista da educação física que predominou de 1930 a 1945, tinha como discurso fundamental a idéia de preparar cidadãos fortes e bem treinados para enfrentar os desafios da vida e possivelmente os desafios nos campos de 
Ano XXI, n 32/33, junho e dezembro/2009

batalha, amparada ainda em numa concepção de civismo e de amor à pátria de forma inquestionável.

Destas duas tendências que marcaram e ainda marcam a prática da educação física escolar em alguma ou em grande medida, a higienista e a militarista, ambas, do ponto de vista metodológico e epistemológico, se baseavam no ato de ensinar a educação física por meio de uma relação de comando e obediência: de um lado, o instrutor-professor; de outro lado, o aluno-obediente e disciplinado; cabe ao professor comandar e aos alunos obedecerem de maneira inquestionável tal comando para poderem internalizar auto-controle, disciplina e retidão na realização dos movimentos e no trato e cuidado com o próprio corpo. Daí a presença marcante nos períodos supracitados da estratégia de se trabalhar com crianças sob a forma de contestes e de exacerbar a idéia de controle da aula por meio das filas e das colunas, lembrando a ordem unida dos quartéis, bem como, a necessidade de separação entre meninos e meninas durante as aulas de educação física, evocando a idéia da performance e do preconceito social ao conceber a mulher como menos apta e incapaz de realizar os movimentos como os homens.

Com a década de 1970, e principalmente fomentado pelo programa federal EPT (Esporte Para Todos) difundido em cadeia nacional e anunciado pelos meios de comunicação de massa, a educação física escolar tende a agregar o ensino do esporte como o seu conteúdo privilegiado, mas sem perder o foco da saúde individual, fundada na idéia de um organismo higiênico e portador de um corpo e de uma mente sãos. Ou seja, a tendência higiênica e militarista ainda eram os maiores fundamentos do trabalho do professor de educação física na escola, o que alterou um pouco foi a internalização de que o esporte era o conteúdo por excelência a ser praticado e ensinado na escola, permanecendo sempre como fulcro a ideia de higiene e da saúde orgânica. $\mathrm{O}$ dado novo é que a dimensão competitiva da sociedade como um todo passa a ser o exemplo de força, de altivez, de garra e de determinação na direção da "ordem e do progresso social". Os esportes competitivos de rendimento passarão a ser o emblema motivador deste novo horizonte da educação física e de seus alunos, possíveis futuros atletas.

Nesse sentido, a esportivização dentro das aulas de educação física ganha cada vez mais corpo e força, principalmente por meio dos estudos sobre o treinamento desportivo. Há o desenvolvimento das escolinhas de iniciação esportiva, 
os jogos estudantis e as olimpíadas escolares, uma vez que pois, o futebol é o ícone do esporte de alto rendimento bem sucedido no Brasil, vitorioso. Principalmente através pela conquista da copa de 1970, sua repercussão mundial e a consolidação das figuras de Pelé, Garrincha e companhia como jovens que vieram de uma classe social pobre e conseguiram fama, dinheiro e projeção internacional para o país em relação ao mundo. $\mathrm{O}$ esporte torna-se uma realidade nacional na fomentação dos desejos de milhares de crianças e impulsionador de um mercado que envolve desde profissionais técnicos, passando pela indústria dos materiais e equipamentos esportivos, até se transformar-se em um negócio rentável e politicamente significativo, pois mobilizador das grandes massas.

Mas é na década de 1980 que acontece um verdadeiro "boom" da produção intelectual na Educação Física Escolar. Em 1983, a professora Vera Lúcia M. Costa recebe o prêmio MEC de Literatura Desportiva, com o livro, Prática da Educação Física no $1^{\circ}$. Grau - Modelo de reprodução ou perspectiva de transformação?. Nesta obra, fica clara a presença de um olhar crítico sobre a ação do professor de educação física na escola, à luz de teorias advindas do campo das Ciências Humanas e principalmente das Ciências Sociais, pois que trata de situar o professor como educador e também como um interventor social que, ao ensinar a educação física, veicula valores morais e ideológicos.

Já o professor Alfredo Faria Júnior, lança em 1986, a Didática de Educação Física - Formulação de objetivos, um ícone da didática brasileira, que visa a fundamentar a prática da educação física na escola e sua estreita vinculação com a educação, difundindo a idéia de que os cursos de formação em educação física não podem prescindir do ensino da didática e dos estudos educacionais. Esta obra marca uma nova era na educação física do ponto de vista do início de uma tentativa de fundamentar e de sistematizar a educação física dentro do campo pedagógico.

Numa outra dimensão, mas articulado com o seu tempo presente, o prof. Tubinho em 1986, lança As dimensões sociais do esporte, que trata de situar a diferenciação entre o esporte praticado na escola, no clube, do esporte comunitário. Com esta obra, ratifica-se a idéia e a compreensão de que a educação física que atua na escola visa a formação de um outro perfil de aluno, portanto, fazem-se necessárias novas metodologias de ensino, pois os objetivos são distintos em cada uma das dimensões citadas.

Em 1988, Kokubun, Proença, Manoel e Tani, escrevem um 
Ano XXI, n 32/33, junho e dezembro/2009

importante livro intitulado Educação Física Escolar - Fundamentos de uma abordagem desenvolvimentista que irá fundamentar os cadernos do MEC na orientação e na fundamentação dos conteúdos da educação física em território nacional. Obra essa que até hoje não pode deixar de ser citada e estudada pelas novas gerações, mesmo que à guisa de ser criticamente ser repensada sua proposta ou mesmo de superá-la à luz de novos estudos e teorias.

Nesta mesma época surge um outro brilhante trabalho do professor Paulo Medina (1983), A educação física cuida do corpo... e "mente", que contribui para o pensamento sobre a Educação Física Escolar no qual o autor tece críticas sérias sobre as conseqüências político-pedagógicas de se pensar o corpo como metáfora da máquina, dentro de uma lógica cartesiana e dualista de homem. Medina aponta algumas repercussões do ponto de vista ideológico quando há o tratamento do aluno, por parte do professor, de maneira bipartida entre corpo e mente.

$\mathrm{Na}$ década de 1990, a Educação Física Escolar passa a ser objeto de inúmeras discussões do ponto de vista ideológico. Ou seja, não basta mais situar a educação física na escola como sendo uma área pedagógica e que para tanto precisa formar e produzir intelectualmente e materialmente a pedagogia do ensino da educação física, com suas técnicas, com suas metodologias e com seus fundamentos. Faz-se necessário também atentar a que tipo de mensagem e de mensagens a educação física na escola visa reforçar ou transformar enquanto instrumento político e ideológico. Neste momento, entra em cena neste período histórico, mais do que em qualquer outro período, uma avalanche de produção crítica sobre acerca das as possíveis definições sobre o que venha a ser a educação física, qual o seu propósito na escola, qual o seu compromisso do ponto de vista educacional e político-social, quais os valores ideológicos que a educação física escolar carreia ao fazer apologia à lógica da saúde individual, ao desempenho esportiva, à recreação descompromissada, à repetição dos movimentos gímnicos, à estética da forma, o culto à beleza, aos padrões de movimentos, à disciplina e à obediência dos corpos dóceis.

Em 1992, o livro Coletivo de Autores, Metodologia do Ensino da Educação Física, sistematiza uma proposta de definição de educação física considerando os seus conteúdos, os possíveis métodos de atuação e de avaliação da educação física escolar, situando como objeto de estudo a cultura corporal que se manifesta sob a forma de 
jogos, de esportes, de danças, de lutas e dos movimentos gímnicos, proposta esta que irá orientar em grande medida nos dias atuais os Parâmetros Curriculares Nacionais em Educação Física (PCNs).

Da mesma forma, não podemos deixar de mencionar a valiosa contribuição do profo João Batista Freire (1992), em seu livro Educação Física de Corpo Inteiro, no qual o autor busca fundamentar a prática da educação física considerando os estudos da psicomotricidade e da teoria do desenvolvimento da inteligência de Jean Piaget. João Batista Freire sinaliza para a contribuição da psicomotricidade como um importante campo de estudo e de intervenção por parte do professor de educação física, só que compreendida agora como técnica e não como suposta "ciência do movimento humano", agregada ainda aos estudos e às descobertas científicas do psicólogo e epistemólogo suíço Jean Piaget.

Numa perspectiva filosófica, o professor e filósofo Silvino Santin (1992), também fornece uma grande contribuição ao pensar os pressupostos filosóficos e pedagógicos do movimento humano por meio de seu livro Educação Física: temas pedagógicos.

Como a Educação Física tem seus fundamentos na concepção de corpo e movimento, o modo como o professor de Educação Física concebe estes dois conceitos incidirá sobremaneira em sua prática pedagógica, bem como em sua visão de mundo e no significado que ele atribui a sua intervenção pedagógica.

Contudo, é Kunz e Trebels (2006), por meio de uma coletânea de capítulos organizados sob a forma de livro, faz um questionamento central sobre as propostas de intervenção por parte do professor de educação física no âmbito da escola, a saber: Como pensar qualquer tipo de intervenção e de reflexão crítica sobre a realidade, uma vez que não se considera os sentidos, os significados, em uma palavra, as representações dos alunos? Nesse sentido, faz-se necessário tecer algumas breves considerações sobre o alcance e a concretude conceitual das representações sociais dentro do campo interdisciplinar do imaginário social.

\section{As representações sociais no contexto do imaginário}

Castoriadis (1982) irá dizer que as representações de um indivíduo são um magma, pois toda representação remete a uma outra representação. Se penso na bola como jogo, posso também pensá-la como mundo, como círculo, como lugar sem saída etc. Toda consciência é 
sempre consciência de... Mas a representação não é necessariamente representação de... "A representação é a apresentação perpétua, o fluxo incessante no e pelo qual se dá. Ela não pertence ao sujeito, ela é, para começar, o sujeito" (375). Ou seja, não é possível conceber uma percepção fora da linguagem, pois se assim concebêssemos, teríamos que admitir que a significação se encontra-se fora do fazer do sujeito. A linguagem não é somente instrumento de comunicação entre diferentes consciências, ela é fundamento da consciência com ela mesma.

Nesse sentido, as significações não se esgotam nunca num campo único de determinação, ao contrário, encontram-se abertas a uma infinidade de determinações. É nesse sentido que não se pode atribuir de maneira fechada e definitiva qualquer tipo de intervenção na realidade escolar, pois cada escola pressupõe uma realidade diferenciada de sentidos sobre o ato de educar considerando a produção subjetiva dos alunos, dos professores, dos administradores e da comunidade do entorno que também pode influenciar de maneira significativa nessas representações.

A representação que o indivíduo faz de si, do mundo e dos outros é profundamente vivida como verdade por ele, portanto significativa por excelência. Sua concretude não se encontra na possibilidade de apreensão imediata por meio da sensibilidade, pois não possui forma e conteúdo determinado; não radica também na sua funcionalidade, isto é, no papel imediato e prático que a representação suscita, pois ela é impulsionada pelos desejos e se direciona ao impossível, ao imponderável. Por esta natureza, a representação é a alma das relações sociais. Concreta por que é a partir dela e por meio dela que o homem se fixa simbolicamente no mundo. Realidade e ficção se confundem, pois o real só se concretiza enquanto imediaticidade na medida em que a ficção, o sonho, o devaneio e a força da imaginação se apresentam enquanto componentes impulsionadores, motivadores, construtores de "objetos" de desejo a serem perseguidos.

\section{Instrumento metodológico}

Foi aplicando 1 questionário do tipo aberto a 16 professores de Educação Física que atuam na rede pública do ensino fundamental, na região metropolitana do Rio de Janeiro, escolhidos arbitrariamente, a fim de mapearmos seus discursos e os fundamentos que justificam as suas intervenções pedagógicas. $\mathrm{O}$ número de dezesseis informantes deu-se em função de uma grande dificuldade por conta dos alunos 
de iniciação científica em conseguir autorização por parte das escolas de aplicarem o questionário com os professores. Assim, optou-se na estratégia de inquiri-los na saída da instituição, e como uma boa parcela dos professores contavam com outros compromissos depois do trabalho na Escola o número de dezesseis informantes foi o possível no espaço de dois meses de pesquisa de campo, considerando ainda, uma demanda de tempo que deveríamos ter para transcrever e analisar as entrevistas.

As respostas dos questionários foram analisadas mediante o procedimento de Análise do Discurso na perspectiva de Dominique Maingneau e de Eni Pulcinelli Orlandi (1992 e 1993), no qual privilegiase o modo de produção discursiva e os sentidos que elas evocam.

\section{Apresentação e considerações sobre os dados da realidade}

a) No universo dos informantes entrevistados, quando foram perguntados se gostariam de continuar trabalhando na escola, a grande maioria disse que sim se as condições de trabalho e de salário fossem modificadas para a maior valorização do professor. Os demais responderam que abandonariam a Escola e alguns optaram por uma nova atuação em âmbito universitário de ensino.

Isto demonstra, ao contrário do que comumente se pensa em relação à formação do professor de educação física na universidade, que há uma adesão significativa dos professores que atuam na escola, mas que, por outro lado, esta adesão fica constantemente comprometida por conta do descaso das políticas de educação dos sucessivos governos em não valorizarem de fato o papel desempenhado pelo professor. Não há como enganar,; o que fica claro em relação às falas dos informantes é que além do salário mais digno e justo, será necessário, segundo eles, que as condições materiais e de infra-estrutura física possam garantir condições objetivas para que seja possível o desenvolvimento de excelência do trabalho a ser prestado. Sobre a parcela que diz querer abandonar a Escola, incidimos a hipótese de que esta corrobora também com a insatisfação dos demais em relação ao descaso salarial por parte do poder público e também em relação à precariedade das condições de trabalho, uma vez que não foi perguntado sobre tais motivos. A minoria que diz querer atuar no âmbito do ensino universitário, sinaliza para o fato de haver professores, que possivelmente estando em um outro nível de intervenção, podem continuar 
Ano XXI, n 32/33, junho e dezembro/2009

se preocupando com a temática da escola, porém, em uma condição um pouco mais satisfatória, seja do ponto de vista das condições materiais e físicas que poderão encontrar ainda em muitas instituições de Ensino Superior.

b) Quando os professores são perguntados em relação aos tópicos que eles qualificam como fundamentais para compor uma palestra para jovens professores de Educação Física que irão começar a atuar no Município do Rio de Janeiro, o tópico sobre a orientação dos valores morais como respeito às diferenças, inclusão social, orientações para a sexualidade, respeito à comunidade, respeito aos recursos materiais, respeito aos colegas e ao próprio professor se apresentam imperiosos. Agregado a isto, ficou nítida a preocupação com uma intervenção da Educação Física voltada para a formação do cidadão, considerando: a criatividade durante o processo do ensino e da aprendizagem, a necessidade de se problematizar questões durante as aulas para serem objeto de reflexão e de atenção e por fim, as condições precárias que se enfrentam em muitas escolas do Município.

Parece-nos que a preocupação com as orientações e a formação moral dos alunos sinaliza para o fato de que os alunos que se encontram no município trazem marcas problemáticas de casa e que se o professor de educação física não estiver atento e com uma boa orientação teórica e metodológica para lidar com estas questões concretas, a sua intervenção ficará muito comprometida.

Também ficou marcante, de acordo com a fala dos professores, o compromisso de uma formação voltada para a cidadania. Ainda que eles não apontem com maior clareza o que venha a ser cidadania, o fato de apostarem em um objetivo que não seja imediato e que não se encontre restringido à aquisição de uma determinada performance ou de ganho técnico por parte do aluno, a nosso ver, trata-se de um avanço. $\mathrm{O}$ que não significa dizer que a Educação Física não deva ensinar os fundamentos técnicos dos movimentos e de seus conteúdos, bem como, atentar-se para as questões de intensidade e de orientação preventiva para a saúde, muito pelo contrário, deve sim compreender que estas e outras questões têm de estar alinhadas a um perfil de sujeito que se almeja formar, considerando a proposta pedagógica da escola, a proposta pedagógica do município e a percepção político-ideológica do próprio professor em relação ao seu papel de formadores de sujeitos para o mundo.

c) Em relação aos argumentos que justificam a relevância 
das aulas de Educação Física, o que se apresentou em destaque foi o fato de que a Educação Física é representada como uma Disciplina que promove o desenvolvimento integral da criança, isto é, segundo os informantes, nos aspectos motor, psicomotor e social.

Quando se elaborou esta questão e se disponibilizou para os professores um espaço para uma resposta detalhada e consistente, esperávamos argumentos, isto é, os porquês, e não simplesmente frases de efeito. E isto, a nosso ver, se deve-se à própria dificuldade interna da profissão que ao longo de sua história passou por várias influências ideológicas e políticas e só muito recentemente, a partir da década de 1980, começou a elaborar uma reflexão mais crítica e sistemática acerca do papel do professor e da educação física enquanto intervenção pedagógica.

d) Na questão que se pergunta sobre os conteúdos de ensino da educação física escolar, a expressiva maioria dos informantes afirmam ser: as habilidades motoras, os fundamentos esportivos e o desenvolvimento da psicomotricidade.

Esse achado nos indica que ainda há certa falta de adoção ou mesmo de adesão, por parte dos professores, em considerarem as orientações dos Parâmetros, pois confundem fundamentação técnica como psicomotricidade, desenvolvimento de habilidades motoras e aquisição de fundamentos esportivos, com conhecimento de ensino.

e) Quando foram perguntados se havia diferença entre os termos ou conteúdos: jogo e esporte mais da metade dos informantes identificaram a presença e a apropriação das regras e da competição como elementos diferenciadores do esporte em relação ao jogo. O que atende muito parcialmente, pois no livro de Retondar (2007), este aponta com clareza os pontos comuns e de afastamentos entre jogo e esporte.

f) Já em relação às possíveis diferenças entre dança e ginástica, o argumento central aponta para a idéia da dança enquanto movimento voltado para uma maior expressividade e criação dos movimentos, enquanto a ginástica se justifica por ser movimentos mais repetitivos e atrelados à saúde e ao bem estar. A funcionalidade da ginástica também pode ser apropriada pela dança, como exemplo, tem-se a dançaterapia.

g) Para a diferenciação entre luta e briga, o que predominou nos discursos foi o fato de que na luta há a presença e a necessidade de um domínio técnico e de regras, bem como, a necessidade de um responsável para ensiná-las. Muitos ainda afirmam que por conta disto ela também é um desporto. Já a briga, 
Ano XXI, n 32/33, junho e dezembro/2009

por oposição à luta, se apresentou como a expressão destrutiva advinda de um comportamento violento.

O que interpretamos sobre as possíveis diferenças conceituais entre jogo e esporte, dança e ginástica e entre luta e briga, analisados aqui em bloco, é que as respostas caminham num sentido de confusão e de carência de maiores aprofundamentos conceituais sobre tais conhecimentos, ainda que não se trate de dizer que as respostas estejam erradas ou certas, até porque teríamos que eleger alguns parâmetros e estes se apresentam diversificados e neste espaço não temos como fazê-lo . O fato é que as respostas apontam para uma percepção simplista e denotam certa falta de importância por parte dos professores em considerar como sendo importantes para sua intervenção estabelecerem diferenciações conceituais sobre os conteúdos supracitados. É como se fossem óbvias por demais as diferenças entre os conteúdos e que a própria intuição pessoal e a vivência do professor fosse suficiente para dar conta de sua intervenção, na medida em que ir, além disso, seria buscar algo muito "teórico" e distanciado de sua prática cotidiana. E aí, provavelmente esteja aparecendo de maneira subjacente a incansável questão e a recorrente tensão entre teoria e prática dentro do processo pedagógico. A primeira remetendo ao mundo das idéias e do "abstrato" e a segunda ao mundo da prática, isto é, daquilo que é "concreto". E sem maiores delongas sobre esta questão, tudo que é passível de ser pensado e sistematizado do ponto de vista teórico tem como fundamento a realidade, da mesma forma, toda ação prática baseia-se em parâmetros, em pressupostos, em escolhas por parte do sujeito. Portanto, a separação entre teoria e prática só pode ser pensada dentro do escopo da ação pedagógica enquanto um artifício didático, somente nestes termos.

f) $\mathrm{Na}$ questão em que se pedia para se contextualizar a prática do queimado para alunos de 7 a 8 anos e de 12 a 14 anos, em relação aos objetivos de ensino, ficou evidente que ao se trabalhar com o queimado para um grupo etário de 7 a 8 anos, o argumento principal advém do desenvolvimento da psicomotricidade e do aprendizado de regras simples. Já para o grupo etário de 12 a 14 anos, o argumento foi a adoção de regras mais complexas.

Ainda que os argumentos limitem-se à psicomotricidade e à complexidade das regras, que é um argumento tecnicamente possível, as respostas ainda se encontram muito indeterminadas em relação à questão do conteúdo de ensino e seu significado dentro do projeto 
pedagógico, pois não há nenhuma menção clara e fundamentada sobre a importância teórica dos estudos do desenvolvimento da inteligência, do desenvolvimento moral e do desenvolvimento afetivo-social.

g) Quando da pergunta para diferenciar o futebol praticado e desenvolvido na escola e aquele praticado pelas crianças na rua, os professores argumentam que a diferenciação do primeiro em relação ao segundo reside no fato deste possuir uma maior organização e progressão correta para o aprendizado, no qual a presença de um profissional é fundamental para que isso ocorra, pois, somente este será capaz de administrar os riscos de lesões e possíveis desentendimentos em face da aplicação das regras oficiais. Enquanto no futebol na rua, vigora o sentido de lazer, isto é, uma prática mais criativa, fundada no prazer e na liberdade.

Fica claro em relação a esta questão sobre a diferenciação do futebol praticado na rua e o futebol praticado na escola que este último se diferencia por conta do ensino de seus fundamentos técnicos de maneira progressiva e didaticamente orientado e com o suporte profissional de se administrar possíveis lesões ósteo-artciulares.

Não se pode deixar de se evidenciar que o papel precípuo da escola não é o de formar atletas, mas antes, de formar sujeitos com novos valores morais, com uma nova apreensão intelectual, com novas possibilidades afetivas e de interação social, como também, com uma nova sensibilidade em relação a si mesmo para que assuma novas perspectivas de vida e de mundo, por meio da apreensão de seu corpo e de seus movimentos como uma importante linguagem. Não se pode prescindir dos conhecimentos técnicos no ensino do futebol ou de qualquer outro conteúdo de ensino na escola. Entretanto, quando os professores referem-se ao sentido do futebol a ser trabalhado na escola evidenciando o predomínio do aspecto técnico, o fazem de maneira parcial, pois não fazem menção ao movimento corporal propriamente dito, centrando a atenção somente nos fundamentos e nas regras da modalidade esportiva.

h) Quando perguntados sobre um possível modelo ideal de avaliação das aulas de Educação Física, as respostas foram muito diversas, ainda que o discurso predominante apontasse pra o fato de que a avaliação tem de estar vinculada aos domínios cognitivo, afetivo e motor. Uns poucos se referiram à necessidade da avaliação ter um caráter de continuidade e uma minoria apontou a necessidade de uma avaliação que se preocupasse com a participação dos alunos durante 
Ano XXI, n 32/33, junho e dezembro/2009

as aulas práticas e com a confecção dos trabalhos teóricos.

Esta é mais uma das inúmeras questões que se apresentam delicadas não só na educação física, mas na educação de maneira geral. Avaliar, como sabemos, não é quantificar desempenho ou identificar curvas de nível do aluno, mas antes, julgar o seu comportamento. Avaliar não é medir, mas emitir julgamento de valor considerando o perfil que a escola almeja formar e como a educação física se encontra articulada a este considerando a sua especificidade. E se nas orientações dos PCNs da Educação Física, a avaliação diagnóstica de maneira continuada é a sugestão que se apresenta, pareceu-nos que a preocupação com a continuidade do processo avaliativo não se fez presente nos discursos.

i) Em relação às "marcas" que os professores de Educação Física querem deixar em seus alunos, em ordem crescente e em nível de prioridade foram: o respeito, a percepção de uma vida ativa e saudável e da qualificação dos alunos para poderem viver em grupo.

É muito interessante que, ainda que por caminhos contraditórios e altamente diversificados, a preocupação do professor de educação física seja a de formar pessoas melhores preparadas do ponto de vista moral. Mesmo que não consigam sistema- tizar esta discussão e fundamentá-las teoricamente, bem como, apontando a necessidade por parte dos alunos de perceberem a importância da prática de atividade física voltada para uma vida mais saudável.

j) Na pergunta que procurou remeter os professores a um vôo imaginário de retorno ao tempo em que eles eram alunos de Educação Física e o que gostariam de dizer hoje, sobre as marcas que se lhes tinham deixado, metade dos informantes disse que diriam muito obrigado e que eles fizeram um excelente trabalho. A outra metade disse que diria a eles que deram uma aula muito pobre, sem se integrar com a escola, que não discutiam diversas questões que ocorriam durante as aulas e que alguns deveriam retornar para a escola para aprenderem sobre a verdadeira Educação Física.

Esta questão aponta para a tensão entre o modelo mais tradicional de ensino da educação física e as propostas mais atuais. E para nós, o que interessa com esta pergunta é que houve uma proporcionalidade entre o saber que era ensinado e o saber que deve ser ensinado e a maneira como deve ser ensinado. Mostrando com clareza que tanto àqueles que buscaram a formação de professor de educação física e tiveram em seu professor certa referência, como àqueles outros, 
que pelas respostas, não viram em seu professor de educação física um exemplo motivador, mas, mesmo assim, assumiram esta formação profissional, seja para reforçar o que aprenderam ou para modificar o que vivenciaram durante as aulas de educação física, optaram pela formação de professores e assumiram a responsabilidade de que é possível e viável educar por meio do movimento.

k) Por fim, ao serem perguntados sobre os documentos orientadores da Educação Física produzido pelo Município, a expressiva maioria disse desconhecer qualquer tipo de movimento nesta direção, cabendo a cada professor se utilizar de suas próprias experiências e convicções acadêmicas para ministrar as aulas.

Independente de a Secretaria de Educação, por intermédio da coordenação de educação física, realmente elaborar ou deixar de elaborar documentos norteadores e orientadores para a ação da educação física, o fato é que os professores apontaram de maneira unânime para a questão da dificuldade da comunicação.

\section{Considerações finais}

Diante dos dados identificados e interpretados, podemos dizer que os professores de educação física que se encontram na escola, na sua expressiva maioria estão aderidos à idéia de que são educadores. E isto aponta para certa repercussão da mudança no pensamento acerca da educação física e de seu papel a partir da década de 1980 e que certamente chegou aos professores entrevistados por intermédio de suas formações universitárias. Haja vista que há uma nítida preocupação em pensar o aluno considerando a sua formação moral e em relação a assumirem uma maior consciência para a necessidade preventiva da saúde através da prática regular de atividade física, ainda que a esportivização durante as aulas e o apego ao ensino técnico ainda permaneçam presentes nos discursos da maioria dos professores, estes não se encontram mais como únicos argumentos.

Trata-se de um avanço histórico, pois isso mostra que hoje não vigora com tanta força a idéia de um professor-treinador ou de um professor-higienista, mas, um professor-formador de valores. Por outro lado, estamos ainda longe de uma orientação clara e teoricamente fundamentada e compromissada com essa perspectiva de intervenção. Afora alguns casos isolados, a maioria dos professores agem de maneira intuitiva e amparados nas suas próprias experiências como fim último. Resistem ainda à idéia de que a reflexão mais sistemática 
Ano XXI, n 32/33, junho e dezembro/2009

e conceitual possa ajudar a sua prática. Daí a dicotomia entre teoria e prática como pólos antagônicos e não complementares e indissociáveis, se apresentando no universo dos professores de educação física por nós investigados.

As questionáveis condições objetivas de trabalho e o evidente descaso e o desrespeito por parte das políticas públicas para com a Educação faz-se notar de maneira clara tanto no que diz respeito à desmotivação por parte dos professores em continuar no magistério, quanto em relação à dificuldade que eles têm em se especializarem para buscarem reflexões mais sistemáticas para pensarem, melhorarem e se motivarem na sua intervenção. Daí a dificuldade em diferenciarem conteúdo de ensino de conhecimento técnico de ensino; de não conseguirem estabelecer de maneira clara os pontos de aproximações e de afastamentos entre os jogos, os esportes, as danças, as lutas e os movimentos gímnincos; da mesma forma no que tange a avaliação como um recurso que aponta a realidade do processo ensino aprendizado sugerindo inúmeras tomadas de atitudes no decorrer do próprio processo.

Ainda que os atuais professores tenham tido motivação ou não das aulas de educação física quando eram alunos, o fato é que por inú- meros caminhos, ser professor de educação física, ao que nos pareceu, é travar uma luta diária contra muitas adversidades, tanto materiais - como a questão salarial injusta e a falta dos recursos materiais didáticos, bem como as questões de infra estruturais da própria escola, como espaço físico adequado -, quanto do ponto de vista estritamente e psicologicamente pessoal, em relação às inúmeras contradições entre o seu pensar e o seu agir.

Faz-se necessário que a comunicação entre professores e coordenação geral do Município se aproxime mais. Que se possa criar canais de comunicação e testá-los a fim de confirmarem sua eficácia para que os professores possam ter uma ação mais na direção de uma unidade do que na pulverização do saber que tratam durante as suas intervenções.

Em função dos achados, pensamos que a imagem do professor de educação física enquanto educador se apresenta fundamentalmente quando pensam na formação e nas marcas que querem deixar nos seus alunos, como aquelas que dizem respeito à formação moral e a certa tomada de consciência da importância do cuidado do corpo como ação preventiva para uma vida mais saudável. Ainda que, esta representação esteja amalgamada a uma série de concepções que 
podem, à primeira vista, apontar para o caminho contrário, como, por exemplo, a ideia de redução dos conteúdos de ensino aos esportes, desconsiderando os jogos, as danças, as lutas e a ginástica; a confusão de habilidades motoras e regras entendidas como conteúdos de ensino e não como competências técnicas. E, por fim, o apontamento da psicomotricidade como um dos fundamentos que justifica a prática pedagógica e que dá suporte para se pensar no dimensionamento do nível de complexidade do ensino considerando as diferenças etárias, mas, esquecendo de apontar e de minimamente refletir sobre outros fundamentos, a saber, os estudos da cognição, do desenvolvimento do sujeito moral, dos argumentos em nome do desenvolvimento afetivo e social e por que não dizer também dos fundamentos estéticos, isto é, da importância do prazer, do fundamento lúdico visando a alegria do movimento e suas repercussões na educação da sensibilidade.

\section{REFERÊNCIAS}

BRASIL. MINISTÉRIO DA EDUCAÇÃO. Secretaria de Educação Fundamental. Parâmetros Curriculares Nacionais $-1^{\text {à̀ }} \mathbf{4}^{\mathrm{a}}$ séries. Brasília: SEF/MEC, v.7, 1997.
. Parâmetros Curriculares

Nacionais em Educação Física $3^{\circ}$ e $4^{\circ}$ ciclos do ensino fundamental. Brasília: SEF/MEC, 1990.

BOULCH, J.L. A educação psicomotora - a psicocinética na idade escolar. Porto Alegre: Artes Médicas, 1980.

BRACHT, W. Educação Física e Aprendizagem Social. Porto Alegre: Magister, 1992.

CASTORIADIS, C. A Instituição Imaginária da Sociedade. Rio de Janeiro; Paz e Terra, 1982.

COLETIVO DE AUTORES. Metodologia do Ensino da Educação Física. São Paulo: Cortez, 1992.

FARIA JR., A.G. Perspectiva na Formação Profissional em Educação Física. In: FERREIRA, N.T. Olhares sobre o corpo e imaginário social. In: Votre, S. (org.).

Imaginário e representações sociais em educação física, esporte e lazer. Rio de Janeiro: editora Gama Filho, 2002.

FREIRE, J.B. Educação de Corpo Inteiro. São Paulo; Scipione, 1992.

HILDEBRANDT, R. Concepções Abertas no Ensino da Educação Física. Rio de Janeiro: Ao Livro Técnico, 1986.

KUNZ, E. e TREBELS, A.H. (orgs.) Educação Física Crítico 
Emancipatória. Rio Grande do Sul. Unijuí, 2006.

LEFEBVRE, H. A vida cotidiana no mundo moderno. São Paulo: Ática, 1991.

MAINGUENEAU, D. Termos chave da análise do discurso. Belho Horizonte, UFMG, 1998.

MEDINA, J.P.S. A educação fsica cuida do corpo e..."mente". Campinas: Papirus, 1983.

ORLANDI, E.P. As formas do silêncio: no movimento dos sentidos. Campinas: UNICAMP, 1992.

PIAGET, J. A Formação do Símbolo na Criança. $2^{\mathrm{a}}$.ed. Rio de Janeiro: Zahar, 1975.

RETONDAR, J.J.M.. Teoria do Jogo - A Dimensão Lúdica da Existência Humana.

Petrópolis: Vozes, 2007.

SANTIN, S. Educação Física: Temas

Pedagógicos. Porto Alegre: EST/ ESEF, 1992.

SECRETARIA MUNICIPAL DE EDUCAÇÃO DO RIO DE JANEIRO. Multieducação:
Núcleo Curricular Básico. Rio de Janeiro, 1996.

DA SILVA, A.R. O Discurso Antidisciplinar da Educação Física Escolar. (Tese de Doutorado). Rio de Janeiro: Universidade Gama Filho, 2007.

SOARES, C. Imagens da Educação no Corpo. $2^{\text {a }}$ ed. São Paulo: Editora Autores Associados, 2002.

SCHILLER, F. A educação estética do homem. São Paulo: Iluminuras, 1990.

TANI, G. et al. Educação Física escolar: Fundamentos de uma Abordagem Desenvolvimentista. São Paulo: EPU/EDUSP, 1988.

TUBINO, M.J.G. As teorias da educação física e do esporte: uma abordagem epistemológica. 1992.
Recebido: Agosto/2009 Aprovado: Agosto/2010 